Article

Barriers in Implementation of Sanitation

Projects: A Case Study of Open Defecation Free (ODF) India

\author{
Journal of Development Economics and \\ Management Research Studies (JDMS), \\ A Peer Reviewed Open Access International Journal \\ ISSN 25825119 (Online) \\ 04(04), 1-17, April-June, 2020 \\ @ Center for Development Economic \\ Studies (CDES) \\ Reprints and permissions \\ http://www.cdes.org.in/ \\ http://www.cdes.org.in/journal/
}

\title{
Barriers in Implementation of Sanitation Projects: A Case Study of Open Defecation Free (ODF) India ${ }^{1}$ \\ Muskan Agrawal ${ }^{2}$ Shabarnee Pradhan ${ }^{3}$ Anand Pandey ${ }^{4}$ Badri Narayanan ${ }^{5}$
}

\begin{abstract}
Despite strong emphasis of government to make India open Defecation free by 2019, open defecation is widespread in India. It is equally widespread in the state of Uttar Pradesh. It is known that good health has strong impact on the overall productivity of an individual. It is also known that good sanitation and hygiene conditions are prere of good health. People are not willing to change their habits and behaviour for healthy sanitation practices. Despite repeated efforts of government to change the behaviour of people regarding construction and use of toilet, people are not changing their habits. Our report presents evidence from the survey data collected from the rural households of Suriyawan block from Bhikarirampur village of Bhadohi district of Uttar Pradesh. More than 70 percent of people we interviewed, told that they do not have enough money for constructing toilet because more than 75 percent of the people think that constructing a toilet requires anything between INR 20,000-30,000. They do not have the idea about the low cost toilets, which they could have easily afforded and used. Also there is a wide spread belief among people that the low cost twin-pits toilets constructed by the government are of inferior quality. Families having working toilet inside home also had at least one member who defecates out in the open. We found that there are many false beliefs among people about open defecation. They possess the mind-set that open defecation improves their health as they get fresh air and defecate in the open in an open space. Females believe that using household toilet causes headache and sickness. Many believe that household toilets require more water, therefore it's better to defecate in the open. Male members considered household toilet are for only females. Another important finding was lot of people do not want to construct a toilet because they think maintenance and cleanliness of the latrine is a big headache. These findings
\end{abstract}

${ }^{1}$ We would like to thank the management and faculty members of Xavier School of Rural Management, Bhubaneshwar, particularly Prof $\mathrm{T}$ Kumar, as well as Fundamental Action and Research Foundation, particularly Mr Ramdutt Mishra, Mr Rishi Raj Mishra and family of Bhikarirampur, UP, for facilitating our field visit.

${ }^{2}$ Graduate Student, Xavier School of Rural Management, Bhubaneshwar, India

${ }^{3}$ Graduate Student, Xavier School of Rural Management, Bhubaneshwar, India

${ }^{4}$ Founder, Fundamental Action and Research Foundation, India

5 Advisor, Fundamental Action and Research Foundation, India, Affiliate Professor, University of Washington Seattle and Co-founder and Partner, Infinite Sum Modelling, USA, Corresponding author. 
suggest that stakeholders need to intensify and stress on the Behaviour change communication strategies to nullify the widespread false beliefs among people regarding toilet use.

Keywords: Health, sanitation, open defecation, dignity, hygiene, diseases, toilet, behaviour.

\section{INTRODUCTION}

Use of Toilet is an important aspect of personal hygiene and sanitation as it affects the overall health and well-being of an individual. The practice of open defecation affects the health status of a human being. Moreover, it affects the dignity and privacy of women. It is evident from the previous research that very less number of Indian households has access to household latrines. In addition, there are many barriers, which prevent individuals from use of toilet in spite of having toilet.

The practice of open-defecation is widespread in India. It poses a critical health hazard to millions of people. The Mission to make India Open defecation free has been enshrined in the Government's "Swachh Bharat Mission". Indian government strives to make India open defecation free by 2 October, 2019 on the 150th birth anniversary of father of nation, Mahatma Gandhi. Good health ensures better work productivity thus improving economic conditions of rural poor. Proper sanitation facilities are important components for better health. Considering the fact that better sanitation facilities improves economic status, Government of India (GOI) plans to construct toilets in the rural households to increase the access of rural people to toilets. Moreover, it will implement the strategies for behavioural change related to various myths and beliefs regarding use of toilet. We expect that this report on various barriers regarding construction and use of toilet would be helpful to Fundamental Action and Research Foundation (FARF) in effective implementation of the strategies to make Bhikarirampur Open Defecation Free (ODF).

\subsection{BACKGROUND}

In 2011, the sanitation coverage globally constituted to about 64 percent. While there is claim of open defecation declining across the globe, 15 percent (one billion) of the global population are still defecating outdoors. Whereas some countries have substantially reduced open defecation to only a few percent, India and 26 other countries still remain with more than one-fourth of their populations practicing OD. Again, among the one billion defecating in the open globally, majority (66 percent) of them live in India itself and nearly all (92 percent) of these Indians live in rural areas.

"According to the most recent Swachhta Status Report by the National Sample Survey Office (NSSO), in 2015, about more than half of the rural population i.e. 52.1 percent of the country still defecates in the open". Despite consistent efforts from the Government for the last three decades to promote sanitation in India, it has barely been able to achieve its "Millennium Development Goal" i.e. target to free halve the proportion of the global population living without access to safe drinking water and basic sanitation by 2015 .

Efforts to increase rural sanitation coverage in India majorly begun with the establishment of Central Rural Sanitation Programme in 1986 (CSRP). This subsidy-based initiative to promote sanitation did not yield any substantial impact, and then CRSP was replaced in 1999 with the Total Sanitation Campaign (TSC). Along with providing subsidies to facilitate households below poverty line (BPL) to build latrines, the new programme was improvised to make it participatory and more community-based. 
Uttar Pradesh, in northern India, is among the lowest performing states in terms of latrine coverage. In 2013, almost 85 percent of the total rural households (HHs) defecated in the open and latrine coverage increased marginally by seven percentages only between 2001 and 2011, reaching to something about 22 percent. Those that owned a latrine often did not use it on a regular basis. Usage of latrines and latrine sanitation is not at all encouraging and this is true for all over India. "According to a national survey done in 2010, it was found that even in rural areas which were designated open defecation free (ODF), around 50 percent of the newly constructed toilets were not utilised. Only in some high coverage rural areas of Uttar Pradesh, 83 percent of households had toilets, but just about some 48 percent of them were reported of actually using them".

\subsection{CONCEPT}

Health, sanitation and hygiene are important factors for socio-economic development of a community. Good health and sanitation practices reduces the risk of acquiring diseases, thus saves individuals from monetary expenditures. Good health also ensures better work productivity, which in return improves household's economy. Poor sanitation and unhygienic conditions are the key causes of poor health, diseases and mortality, especially among children. The effects of poor sanitation permeate into every aspect of life; economic, health, education, nutrition, dignity and empowerment, stemming into an unending cycle of poverty and deprivation. The four critical sanitation and hygiene behaviours include: Construction and use of toilets; safe disposal of child faeces, hand washing with soap and after handling child faeces, safe storage and handling of drinking water. These factors become much more critical in context with the developing countries where child mortality, premature death, malnutrition, underweight and stunted growth of child are area of serious concern. There are many social, economic, cultural as well as psychological barriers, which keeps community members far from the use of household toilets. There are many gaps in the strategies adopted by the Government and other stakeholders to create awareness among community members regarding construction and use of toilets. Behavioural change is one of the important aspects, which can affect the state for use of toilets.

Most of the previous programs related to making communities Open Defecation Free failed because the Government focused more on the development of infrastructure i.e. construction of community and individual community toilets without creating a demand for toilets. Therefore, since there was no intact policy for Behavioural change among the community members, they preferred going out in the open for defecation in spite of having access to toilets inside home. Therefore, developing of a Behavioural Change Communication (BCC) strategy is much needed for creating demand of toilets and related desirable change in the community people regarding various health and sanitation practices.

Behavioural Change Communication (BCC): Behavioural change communication strategy involves awareness building, dissemination of knowledge regarding various practices of sanitation at individual and community level. Change in behaviour is a critical issue to overcome. Peer pressure of the fellow community members can help in changing the rigid social norms prevalent in the community. For this interpersonal communication and use of different mass media tools would be helpful to generate awareness.

BCC is the comprehensive process in which one passes through the stages:

Unaware $>$ Aware $>$ Concerned $>$ Knowledgeable $>$ Motivated to change $>$ Practicing trial behaviour change $>$ Sustained behaviour change

It involves the following steps: 
- State program goals

- Involve stakeholders

- Identify target populations

- Conduct formative BCC assessments

- Segment target populations

- Define behaviour change objectives

- Define BCC strategy \& monitoring and evaluation plan

- Develop communication products

- Pre-test

- Implement and monitor

- Evaluate

- Analyse feedback and revise

Problems in BCC: The required behavioural change for making a community open defecation free involves these four critical issues:

- Ending open defecation

- Building and use of toilets including cleaning (pan and floor area)

- The safe disposal of child faeces

- Hand washing with soap and water after defecation, before preparation of food and after handling child faeces.

\subsection{RESEARCH PROBLEM}

Healthy sanitation and hygiene practices are very much related to the overall well-being of an individual. Use of toilets is an important component of personal as well as community health. Various social, economic, cultural and psychological barriers prevent individual from using toilets. The research identifies these various barriers and comes out with the information, which would be helpful in designing various tools to increase the demand generation regarding construction, use and maintenance of toilets (pit cleaning and composting of human waste).

\subsection{OBJECTIVE OF STUDY}

- To study and examine the existing state of sanitation particularly use of toilets.

- To analyse the behaviours of individuals, community pertaining constructions and use of toilets.

- To understand the opinions and views of community members about the various difficulties regarding access and use of toilets.

- Suggest various strategies for demand creation of construction and use of toilets.

- To compare the standard of latrines being constructed in the village with that of the prescribed standard of latrine by the Government.

\subsection{PURPOSE AND SIGNIFICANCE OF RESEARCH}

The research analyses the various factors that prevent rural households from the construction and use of toilets. The research finds out the various social norms attached to use of toilet. The findings would be helpful in designing the various Behavioural Change Communications strategies in order to push the demand generation regarding construction and use of toilets. This would also help in improving various health indicators of the rural poor in Uttar Pradesh. 


\subsection{ABOUT THE ORGANISATION}

Fundamental Action \& Research Foundation (FARF) is a non-profit organization based in Bangalore. FARF's journey started in 2014 in Bangalore by dedicated people who wanted to work voluntarily for farmers, by creating awareness \& bringing transparency in implementation of government policies. It also aimed at working towards local education, health, transportation and infrastructure development project.

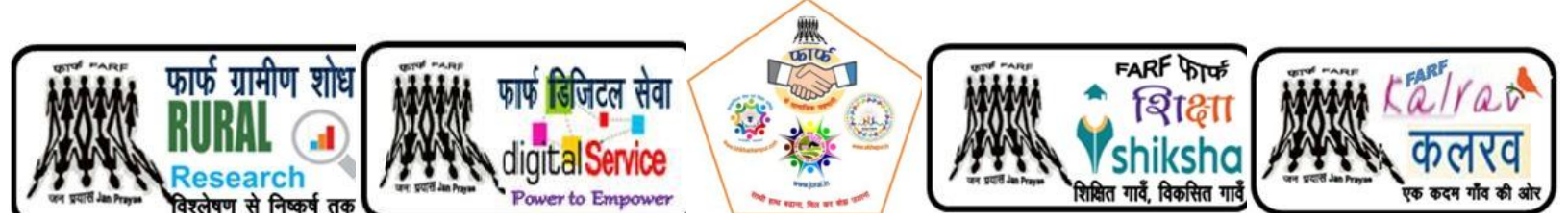

FARF- Fundamental Action and Research Actions, going by its name, focuses on few core verticals in rural development. They are:

\section{Fundamental Action}

- Digital Services: FARF provides digital services to rural people in villages. Digital services include application of Income certificates, Caste certificates, domicile certificates etc. There is no fee for poor people in rural places. FARF provides rural people with all village level details on need basis. This information includes budget/expense on annual finance commission, MGNREGA work, beneficiaries of Indira Awaas Yojna, beneficiaries on Old Age Pension/Widow Pension/Handicapped Pension etc.

- Poor Child Education Support: FARF has adopted around 30 poor children in few villages in Bhadohi district (Uttar Pradesh) and sponsored their school fee, bags, shoes, etc. in a good private school.

- FARF's Adarsh Gram Yojana (FAGY): This is an initiative started by FARF in 2016 by adopting few villages in Bhadohi district, Uttar Pradesh. FARF's research team organized doorto-door survey to understand the socio-economic problems. Open meetings in adopted villages were also organized and ground level problems were documented. Documentaries were also made so that problems could be brought into light in front of decisive authority on social media. Based on the survey work, a comprehensive survey report was prepared in June-2016 and reports were shared with District Magistrate, Chief Development Officer, Block Development Officer, etc.

- FARF adopted around seven villages to make them "ideal villages" and work on rural development at ground level.

- Video Documentary: To resolve the issues at ground level, FARF has made numerous videos and do share with Government officials to look into the matter on urgent basis. Some of the videos are uploaded at the YouTube Channel called "FARF Bhadohi".

- "Kalrav - A Step towards Village" is a five-day rural engagement program that happens in villages of Bhadohi (near Varanasi), Uttar Pradesh. FARF organized it's first such program between 26th June, 2017 to 30th June, 2017. This initiative of FARF is to bridge the gap between our urban and village society and bring meaningful change in people's lives.

\section{$\underline{\text { Research Action }}$}

FARF collects socio-economic and agricultural data through questionnaires and door-to-door surveys and undergoes research to enhance benefits of various planning and strategies. Research work and data sharing is in progress and in collaboration with various research institutes and social sectors. FARF's social media \& digital team shares informative facts with rural people so that they can be well aware and be benefited with ongoing Government schemes. 


\section{SUCCESS STORIES AND RECOGNITION OF FARF:}

- Open Meetings in Adopted Villages was called by Village Secretary on FARF's demand

- Better transparency in few adopted villages by sharing village level details on Notice boards at public places

- Two roads construction were started because of continuous follow-up

- Helped in making few villages digital and creating their own websites

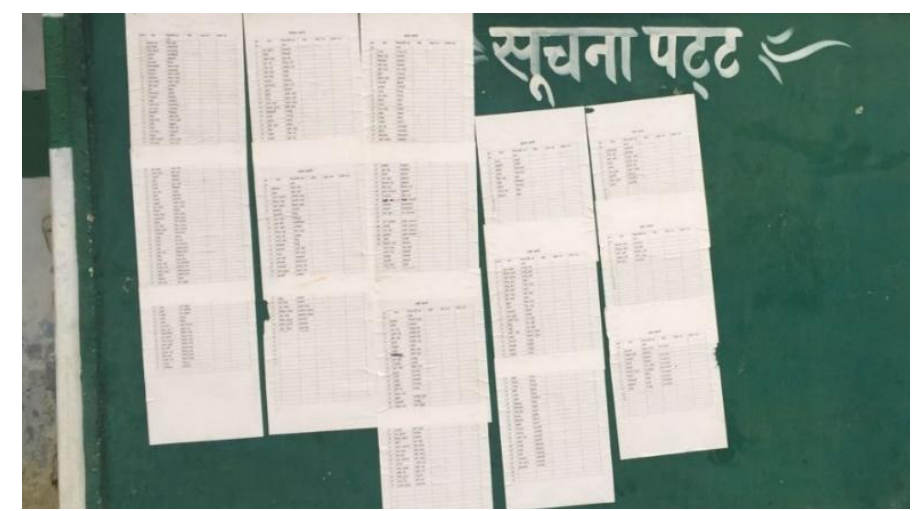

Picture 1: secretary disclosed 325 names in public notice board

\section{CONTRIBUTION OF FARF TOWARDS IMPLEMENTATION OF ODF IN BHIKARIRAMPUR}
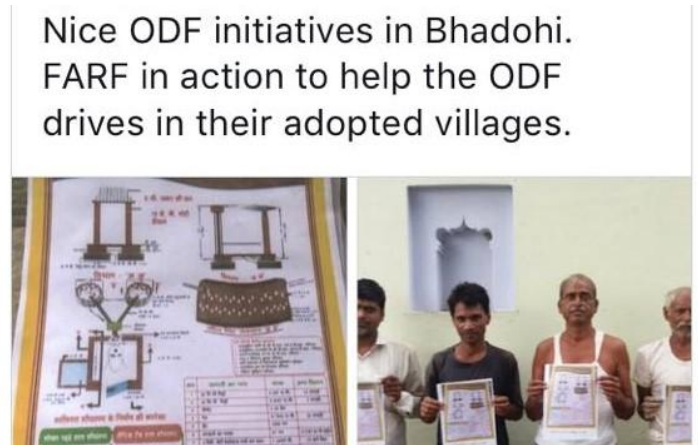

Picture 2: Initiatives taken by FARF for ODF

In light of the present scenario of Open Defecation practiced at Bhikarirampur, FARF has intervened to make the people aware about the various dangers relating to Open Defecation. It has also enlightened people about the Open Defecation Free (ODF) initiative "Swachh Bharat Mission" by GOI.

With the motive to encourage the villagers to build latrines at their house, FARF has even constructed few toilets with consistent efforts and hard work. FARF has also gone forward to the Village Officers, BDO's etc. to extract information about the various schemes working for the village and the list of people eligible for those schemes and benefits from the Government.

It has successfully managed to extract the list of the people whose name are there in the SBM list and posted it on public on forum (School notice board). Therefore, making the people aware of their rights and demanding the same from the Pradhan. 

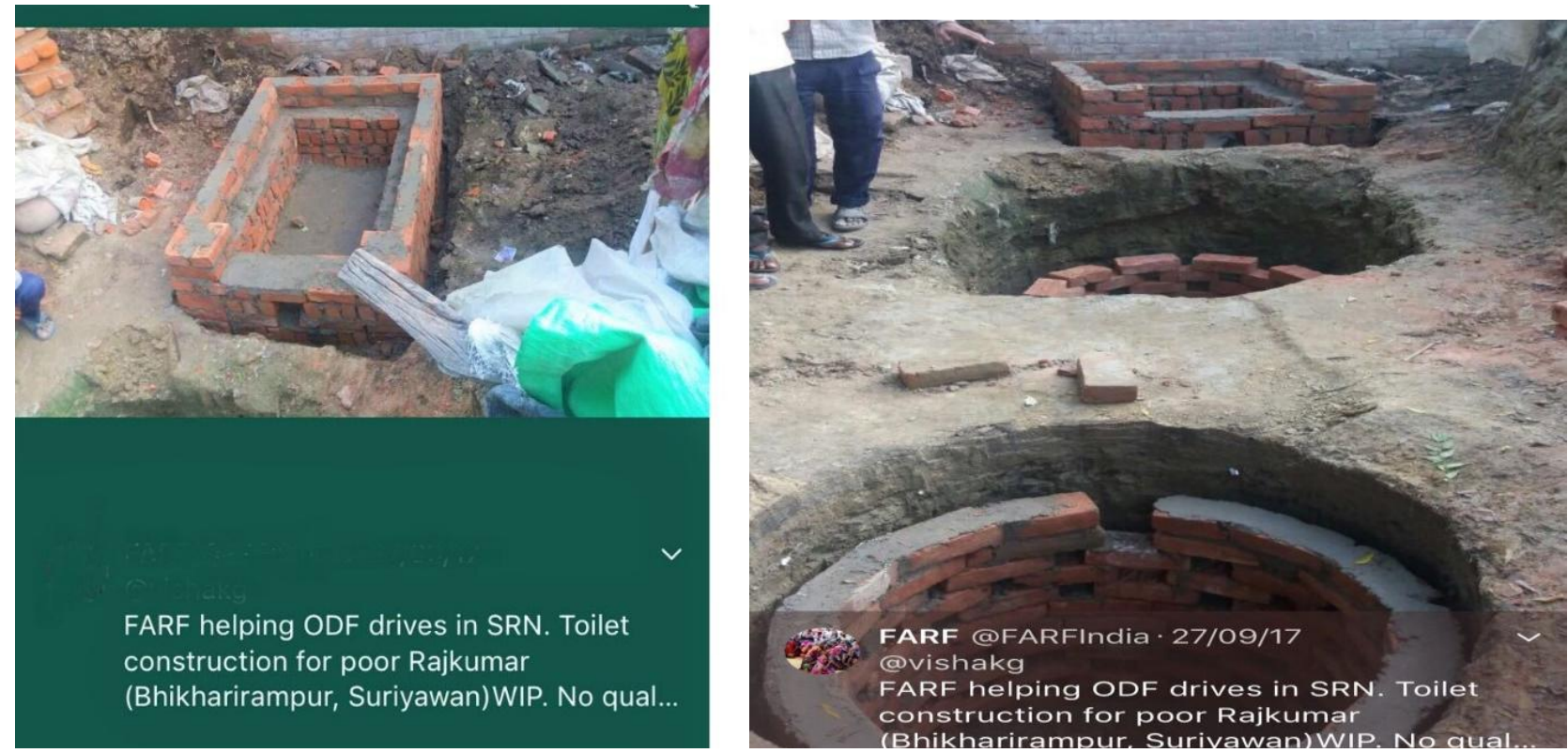

\subsection{RESEARCH DESIGN}

The research design used in our study is Descriptive Research Design; this research design usually focuses on the description of the behaviour of variables under study. The main goal of this type of study is to describe and analyse the data representing the behaviour of the phenomena and their relationships. We started with identifying the research problems clearly with the survey of the existing literature on the topic of our research (Where India goes?). Then we identified gaps in the concepts, methodology, etc. and specified the objective of the study. The research is based upon the study of various behavioural aspects and misconceptions that restricts the rural households from constructing and using toilets, and therefore finding out the answers to our problem statement. It is also a non-experimental research as it tries to find out the causes which hinder rural community from usage of toilets. Also, as the research is meant for academic purpose hence, it is a Cross-Sectional research.

\subsection{SAMPLING}

The universe of the study is the total households of Bhikarirampur, of Suriyawan Block. Being one of the most populous villages in the district, it was nearly impossible to survey every household in such a small span. Therefore, stratified random sampling is used to interview the respondents. Around 50 households approximately were interviewed. The different group of community based on gender, age and economic group was studied. It was nearly impossible to take interview and find out the reasons from the respondents as why they are not using the toilet. Community members feared that action would be taken against them if they will reveal that they are not using the toilet. Therefore, case study method is used to find the various reasons of not using toilet. Around 50 respondents were interviewed both formally and informally.

\subsection{DATA SOURCES}

Members of different households in the village of Bhikarirampur were the source of primary data. The study used both primary and secondary sources of data. Primary data was collected through use of in-depth interview. We conducted both semi-structured and personal interviews. The interview schedule constituted the primary source. Relevant books, journals, news items, newspaper articles and information from the internet served as the secondary data. The primary data collected using 
questionnaire was evaluated by us. The data obtained were first sorted and edited. The data was described and analysed according to the responses from the various categories of the respondents. A simple describe statistical measures such as frequencies was employed. In addition to that, pie-charts, bar graphs and tables were used for the description of the responses.

\subsection{METHODS OF DATA COLLECTION}

In order to know the present behaviour related to use of toilets in different households, onsite inference was used to analyse the behaviour. As, we are studying the behavioural aspect of the phenomenon, a qualitative research approach has been adopted. As the respondents for the primary data were mostly illiterate, so interview and general friendly conversation with them was used to extract information and understand their views regarding the phenomenon of OD. Case Study was recorded manually from different age groups, households, castes and economic standards so as to find the various reasons of not using toilet in spite of having access to toilet.

\subsection{TOOLS OF DATA COLLECTION}

For Inference pen and notepad was used to note down the important facts. Interview schedule was used to get data from various community members regarding their socio-economic conditions and various issues regarding construction and use of toilets. Checklist was prepared in order to conduct Focused group discussion (FGD). Case study was noted down after talking to respondent.

\subsection{Situation analysis: Barriers regarding construction of toilet}

According to Census 2011, 81 percent of the rural households practice open defecation. As per Swachh Bharat Mission (SBM) progress report, 42.77 percent of the households have been provided with house latrines. There are many constraints, which restricts people from construction of toilet. These constraints are non-availability of sufficient money and land, whereas a good number of people considered construction of toilet as government's responsibility.

\subsection{HOUSEHOLDS WITH TOILET}

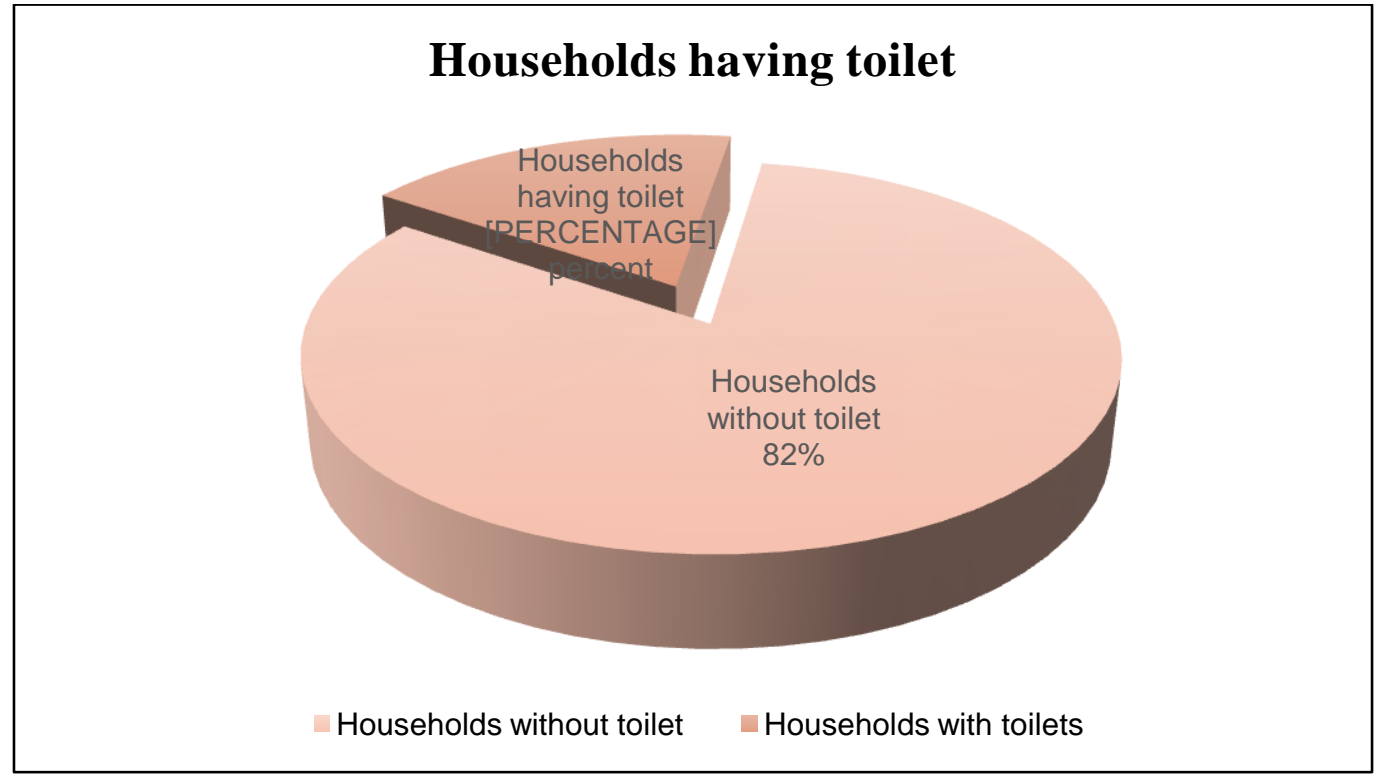

Figure 1 


\section{Inference:}

From figure: 1 we can see that out of total 50 households interviewed, only 18 percent of households have toilet clearly stating the sorry state of the village sanitation status. Remaining 82 percent of households still do not have toilets in their home and practice open defecation.

\subsection{AWARENESS ABOUT SBM}

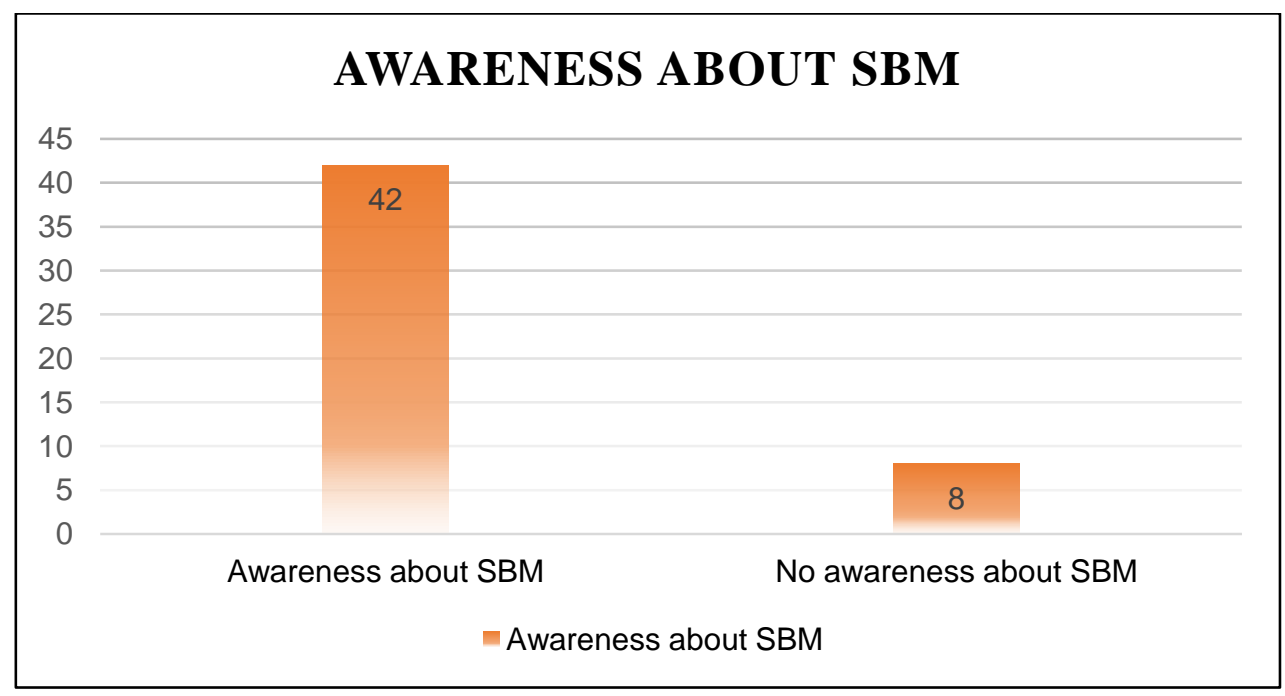

Figure 2

\section{Inference:}

From the above Column graph, we can infer that only 42 out of the 50 households interviewed, are aware about SBM i.e. 84 percent of households and remaining 16 percent of households are still not aware about SBM.

\subsection{REASON FOR NOT HAVING TOILET IN THEIR HOME}

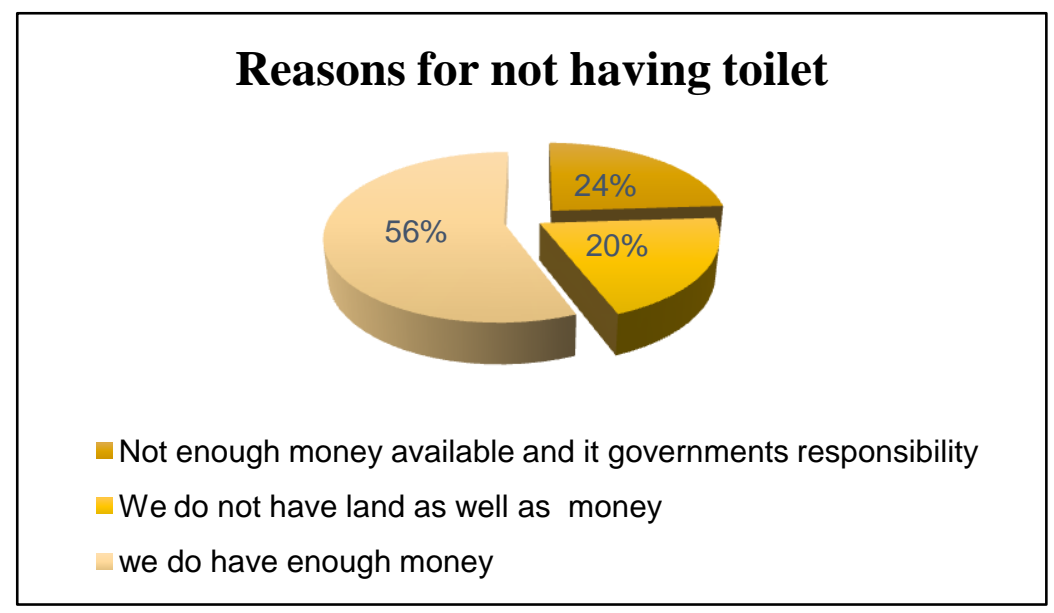

Figure: 3 


\section{Inference:}

From the above chart, it is clear that out of the total number of people interviewed, most number of people (56 percent) didn't have enough money for constructing their toilet while only 20 percent of people don't have land as well as fund to construct toilet. 24 percent of people consider that it is government's responsibility to construct toilet for them as they do not have money.

From the above Percentage pie-chart it is obvious that availability of land for toilet construction is not a big issue in rural area. But most of the people do not have enough money for toilet, it may be concluded that toilet is not in their priority list of things which they wish to have. Also, few people consider construction of toilet is government's obligation.

\subsection{WATER AVAILABILITY IN VILLAGE}

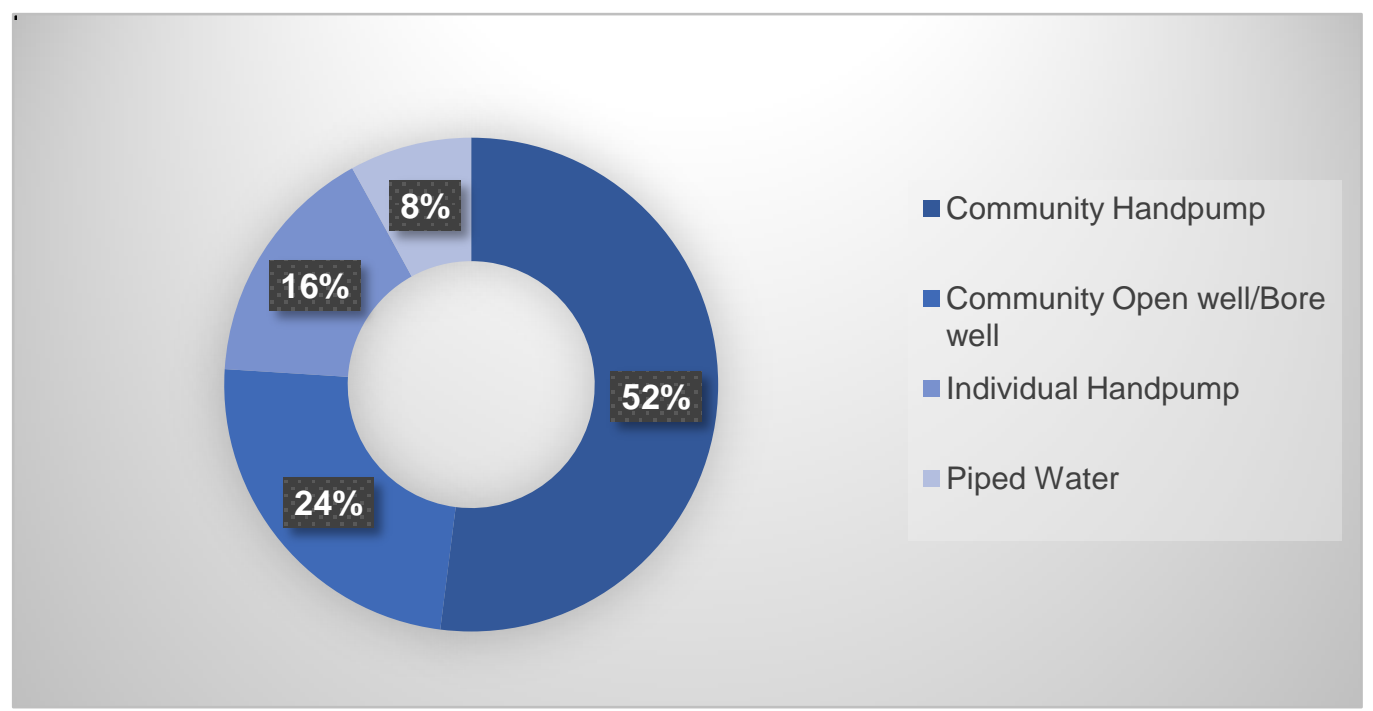

Figure-4

\section{Inference:}

The diagram clearly shows that people have not put in much effort to get water for household use. Around 16 percent of households have individual hand pumps and around 52 percent have access to community hand pumps. Around 24 percent of the people use their community Open well/Bore well for meeting their water requirements. Piped water facility seems like more of a luxury rather than a necessity in this village contributing to just eight percent of the people. It is evident from the above percentages of source of water that availability of water does not proof to be a hindrance towards construction of less number toilets at present in rural households. But distance of the community's hand pumps and Open wells from a given household could be a reason for not constructing toilet. 


\subsection{Distribution of problems faced by females practicing open-defecation}

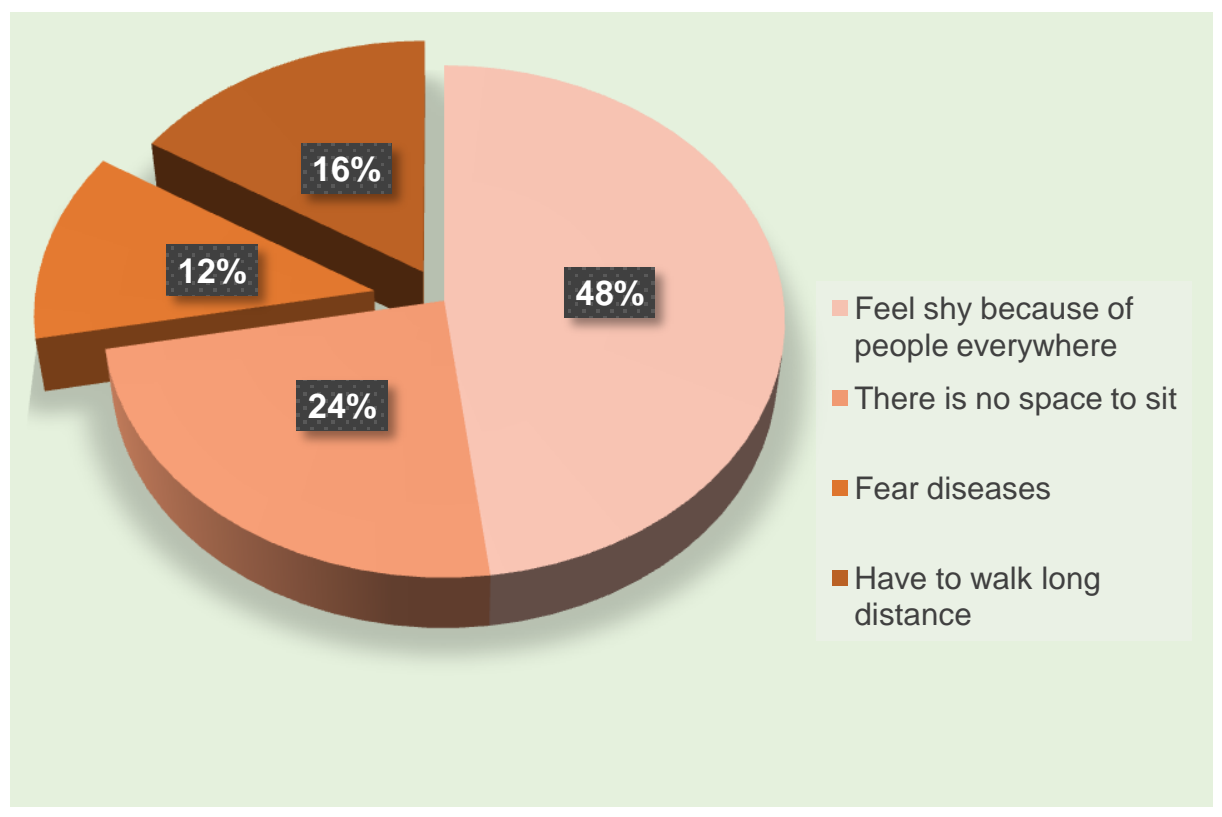

Figure: 5

\section{Inference:}

When we interacted with the female members of the village what problem do they face when they go out for open defecation, maximum (48 percent) number of females told that they risk their dignity every time they go out for defecation. Interestingly, about 24 percent of female members told they were facing a lot of problem defecating in the fields as the village is developing and the villagers are growing crops in the open space there is inadequacy of open space for open defecation. Another bunch of women about (16 percent) expressed their disappointment regarding the long distance they have to travel every time they want to defecate. We were shocked to find out that only 12 percent of the females had an idea that open defecation is a cause of many diseases.

\subsection{Cost for toilet construction according to respondent's view:}

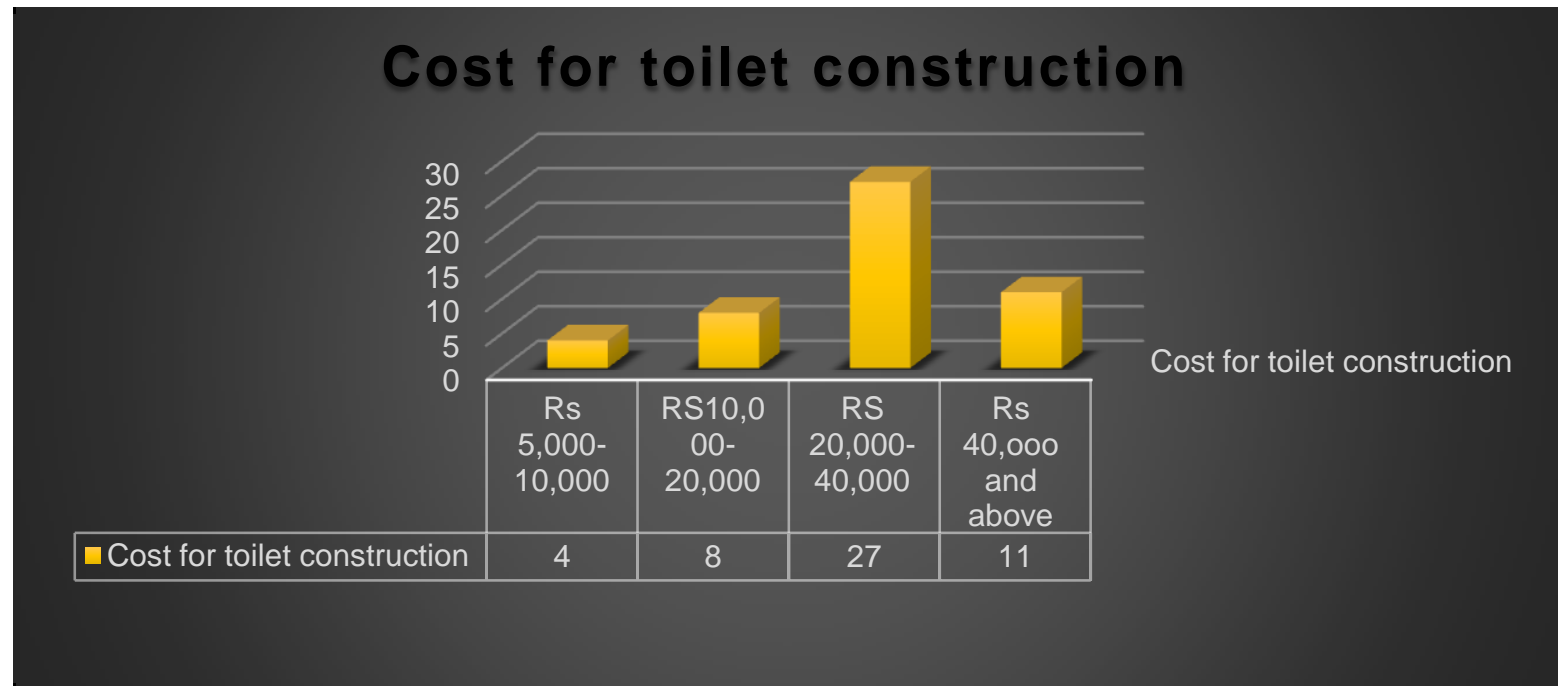

Figure: 6 


\section{Inference:}

From the above bar graph, it is clear that majority of the people think that construction of toilet would cost them something about INR 20,000-40,000. Almost 11 percent of the people told that, a toilet would cost anything between INR 40,000 and above. It may be inferred that the village people over here do not have any awareness about the low cost toilets, therefore a good number of people who could have afforded constructing low cost toilets said that they do not have enough money to construct toilet and have been avoiding construction of toilets at their home.

In addition, when suggested to build twin-pits toilet which would cost less, they told that those are of inferior quality and would not last long.

\subsection{SOME LOOP HOLES IN IMPLEMENTATION OF SBM ON VILLAGE LEVEL}

\subsubsection{OUR FINDINGS}

In Bhikarirampur, twin- pit toilets that are under construction under SBM are not up to the mark as per the actual standards of the government.

- As per the guidelines, the government has allocated an amount of INR 12,000 for each toilet in the households eligible under SBM. This amount should either be transferred to the respective bank accounts of the families eligible under SBM or the Gram Pradhan should facilitate the villagers with all the material and labour required for the construction of the toilet. However, we found that this process is being delayed a lot by the Gram Pradhan in some parts of the village, for example in Vishwakarma, Gond and Saroj communities.

- The Pradhan is taking the sole authority of constructing toilets in the entire village. Whereas, allocated cost set by the GOI per latrine is INR 12,000, the Pradhan manages to construct a latrine of just INR 8,000 by providing the villagers with inferior quality seats, sand, bricks and cement.

- During our interaction with the villagers, we were told that the Pradhan here provides them with no. $2 \& 3$ bricks which are of inferior quality and would not last much, the sand provided to them is not white in colour but of red in colour which is again an inferior quality product.

- We were also told that even the seats provided for constructing the latrines are of extremely cheap quality which would break in the second or third use itself.

- The pits that are being dug are just $3 \mathrm{ft}$ deep whereas the prescribed depth is $4 \mathrm{Ft}$.

- The rooms are smaller than $4 * 4$ metres.

- Due to the lack of space, many toilets are made within less than ten meters of distance from hand- pump. These may lead to the contamination of ground water.

\subsubsection{OUR SUGGESTION}

It is very clear from the above findings, that the people of this village are being cheated by the Village Level Officers. The Pradhan in this village is surely providing the households with the materials for construction of latrines but those are of extremely inferior quality. It looks like people over here are just in the drive to complete the orders given by the GOI regarding SBM within the stipulated time and declare this village as an ODF village. No long-term goal is taken care of. As a result of which most of them have no trust either on the Gram Pradhan or on the Government initiative. This is the sole reason for half of the population of the village not being able to change their mind-set about open defecation and its consequences. These factors act as a constraint in their toilet construction mind-set; they get disappointed by such treachery of the officials and rather choose to defecate in the open. 
Therefore, we suggest a Government intervention should take place in this village. A senior government official should be appointed to come down to this village and inspect the ground level works that are being carried down by the Pradhan and other VO's. Quality check should be the top priority. Once the village is declared ODF, it should not be believed blindly, proper inspection should be carried out only then such loop holes shall be covered and the real problem of OD should eradicate.

\section{Section 4.1 Case Studies}

Case study method was adopted to analyse the mind-sets, behaviours and stigmas related to use of toilet. People were interviewed both formally and informally and their views were noted afterwards. Around ten case studies were taken consisting people from all age group and sex. All ten case studies are given below.

\section{Case:1}

Kamla Sankar Prajapati, 65 is an agri-labourer and has no agricultural land. He works on the agricultural land of Brahmins. He has completed his matriculation. He has two sons and one daughter. His sons work in cloth making factory in Mumbai. He owns a pucca house and has one hand pump in his premises however, has no toilet inside his house. He tells that he has to leave his home early in the morning for working in the fields. Therefore, he prefers defecating in the field, adding to that he is also a heart patient therefore, the doctor has advised him for morning walk.

\section{Case: 2}

Sunita Yadav, 16 lives in a semi- pucca house and has electricity connection at her house. Her grandfather is a farmer and works on his own field. He had constructed a soak-pit toilet outside their house four years back. He had constructed the toilet for his grand- daughters so that they can get some privacy. Still they do not use the toilet and go for open defecation as that is the only time they get to mingle with their friends and spend some time with them. By this practice, they can also look after their fields and get some fresh air. According to them, open defecation is not a problem for them and no one in their family suffers from any kind of disease.

\section{Case: 3}

Naresh Mishra, 58 owns 10 bhighas of agricultural land. He has one son and two daughters. He has electricity connection in his home and has a hand- pump. He renovated his house and made a toilet inside his home when he had his son's wedding. Still his daughters do not use the toilet inside their home as they do not have the habit of sitting in a closed room and feel suffocated. They are happy going in the field early in the morning as they get fresh air. His mother and daughter-in-law use the toilet inside their home regularly and his daughters use it only during emergencies.

\section{Case: 4}

Amrawati Devi, 55 is literate enough to write her name. She has three bhisa agricultural land and lives in a kutcha house. She has twelve members in her family. She is also into one self- help group and last year she had taken loan from her Self Help group to buy one buffalo. She has never thought of making one toilet in her home by taking loan from her SHG group. She does find toilet as a necessity and feels that it is obligation of government. As under Swachh Bharat Mission, toilet is now under construction for their home so they say they will start using it after its completion. 


\section{Case: 5}

Bimlesh Mishra, 48 belongs to the Brahmin caste of Hindu Religion. She told us, she regularly reads newspaper and follows most of the recent programs launched by Prime Minister Narendra Modi. Recently, she has shifted back to the village with her son to take care of her in-laws. Earlier, she used to stay with her husband in Varanasi, who works as a salaried private employee. They have a pucca house in village and have electricity connection. They own six bhighas of agricultural land. They have working toilet constructed inside the house but still no one uses it. On being asked why so, she very casually replied that her old in-laws do not maintain the toilet and that it is always very dirty and cleaning that is a big headache for her. Although she and her son come from a city and have a habit of using toilet, still they go in the field in village and do not feel uncomfortable at all.

\section{Case: 6}

Ishrawati Devi, 37 lives in Bhikarirampur village of Suriyavan block. She belongs to Schedule Caste category. She is illiterate and has eight members in her family. They have a kutcha house and do not have electricity connection. She does not have a toilet in her house and they all defecate in the open. When asked the reason for the same, she said that they do not have enough money to eat and cannot even think of making a toilet.

\section{Case:7}

Mantosha Maurya, 44 who belongs to the Maurya community of Bhikarirampur, has six members in her family. Both of her sons work in Mumbai as salaried private employees. She does not own any agricultural land. They have electricity connection in their home and cook food by LPG. Presently they do have a latrine inside their house. They had constructed that toilet eight months back by their own savings. However, no one in the family uses the toilet as they think that by using the toilet regularly, it's pit would get filled soon and will be of no use after that. In addition to that, she also thinks that toilet constructed is of inferior quality. Therefore, she prefers to go outside in the open field.

\section{Case: 8}

Sanjay Pandey, 45 lives in Bhikarirampur village. He is a priest. He earns his living by performing rites and rituals at other's house and temples. He has a pucca house with electricity connection. He also owns four bhighas of agricultural land. He has a hand pump in his house, but the water layer has gone down so it is not in working condition right now. Therefore, he has to bring water from community hand pump for household use. He had constructed a toilet inside his home some ten years back. Still, his family members prefer to go for open defecation as they get (according to them) fresh air which keeps them healthy. In addition to that, they feel that using the toilet requires more water for its maintenance.

\section{Case 9:}

Anita Devi, 47 belongs to the Harijan community of Bhikarirampur. She owns a semi- pucca house. She has two sons and both of them are married. The main occupation of their family is nonagri labour work. They earn INR 400/- per day. They do not own any agricultural land. They get water from the community open well and do not have electricity connection in their house. She has three grandchildren in her family all below six years. Everybody in her family practices open 
defecation and they do not find toilet as a necessity. They shared that this is a practice which has been followed by their fore- father's generation why should they change it?

\section{Case: 10}

Dinesh Kumar Vishwakarma, 42 belongs to the OBC category and stays in Bhikarirampur. By profession, he is a carpenter and owns four bhighas of agricultural land. He owns a pucca house and has electricity connection in his house. He also has a computer in his house and his sons know how to operate it. He also owns a Tata Ace vehicle, which he had purchased last year by taking loan from the bank. Still they do not have toilet inside their home. When asked for the reason, he said that he does not have enough money to construct a toilet, as according to him it would cost INR 25,000 to INR 30,000 which is a very big amount for them. He does not find toilet as a necessity. He thinks that it is the obligation of government and would surely use toilet if the Government builds one. But he was not willing to spend his own money for construction of the same. Currently, he is worried, as despite of numerous reminders given by him, the Pradhan has not yet provided him the materials for construction of toilet.

\subsection{FINDINGS}

It was found that even where people had an option to use a household latrine, many were reluctant to use them and chose to continue to defecate in the open. Government subsidised latrines were not provided to half of the village yet and even at places where it was facilitated by the Gram Pradhan, it was of inferior quality and mostly remained unused.

- The main reason for latrine installation was the arrival of a newlywed bride into the household, and out of the concern to protect and preserve her dignity, privacy and security as her defecating outside would lower the prestige of the family. However, the same kind of thinking was not followed in the case of the daughters or other female members within the family.

- Women/daughters in law from wealthier or better educated and upper caste families expressed gratitude for the ease and convenience of using the latrine, which normally also included a water supply and private place to bathe, which liberated them from the worry of being seen bathing and defecating in public as it could generate village gossip and family shame.

- In contrast, married women in GOI subsidised latrine households who mostly belonged to the low and middle castes expressed unhappiness for having to use the household latrines as defecating in the open in the evening provided them with a rare daily opportunity to escape the house, the scrutiny of the mother-in-law, and socialise with women friends and peers.

- Women were less concerned about being seen defecating out in the open with the attainment of mother-in-law status and old age.

\section{Poor planning and designs of latrines}

- Problems with inadequate and inappropriate designs and poor and incomplete quality construction of the Government subsidised latrines created barriers to latrine use. Annual risks of monsoon flooding in the area were not considered in the design and construction of the subsidised latrines, many of which had pans installed at or near ground-level and were very small, shallow pits. As a result, many of the toilets had the danger of getting water-logged and unusable in the rainy season.

- Non-involvement of the users in deciding the toilet design to suit their needs and preferences also led to non-use of latrines.

- Households were found to rely highly on subsidies, and the subsidy amount was found to be inadequate to construct a working toilet. 


\section{From the 10 case studies, these below given points are drawn:}

- Adult male population says that they have to go early in the morning for working in their field. Therefore, they do their morning job (defecation) in the field only.

- Few male members argue in support of open defecation citing the reason the going out early in the morning improve their health as they get fresh air.

- Old aged people told that they cannot change their habit and there is no harm in open defecation.

- Few male members consider household toilet is only for female members and they use it only during emergency.

- Female members complained that household latrines smell too much and they get headache and feel sick.

- Few adolescent girls told that it is pleasurable to go out as it gives them chance to mingle with their friends.

- Few old-aged female members feel that household toilet is for young girls as their dignity and privacy is more important.

\subsection{CONCLUSION}

The findings reveal that poor quality and inappropriate latrine designs under government sanitation schemes are important factors, but are not the only reasons for low latrine uptake and use. A number of behavioural aspects constrain the adoption and use of latrines and these vary among communities by gender, age and caste. Any future sanitation intervention needs to consider these aspects and approach the issue of sanitation behaviour change holistically, rather than focusing on targets

\subsection{RECOMMENDATIONS}

- Most of the people told that, they didn't have enough money for constructing toilet because they considered toilet a thing of luxury and very costly, they didn't have the idea about low cost toilet. Therefore, communication tools should be designed so that people get to know about these low cost toilets.

- There is a strong belief among people that low-cost twin pits and soak-pit toilets are of inferior quality therefore they should not consider this toilet for their household.

- There must be an effective media-mix designed to advocate the benefits of low-cost twin-pits toilet so that poor who otherwise think toilet to be costly thing would construct these low cost toilets.

- More and more emphasis should be laid on interpersonal communication tools to educate people about the harmful effects of open-defecation.

- Very less number of people have access to television and radios and media, so posters and wall paintings, pamphlets should find prominent place in the media mix.

- Above all, there must be provision for some kind of punishment for the people who have toilet at home and found defecating in the open. These simple punishments can be imposed by Community Based organizations or the Pradhan. 


\section{REFERENCES}

- Behavioural change communication. Wikipedia: The free encyclopaedia.

https://en.wikipedia.org/wiki/Behavior_change_communication

- Where India Goes

http://velivada.com/2017/08/26/book-review-India-goes-abandoned-toilets-stunted-developmentcosts-caste/http://www.hindustantimes.com/books/excerpt-where- india-goes- by-diane-coffeyand- dean-spears/story-xEmDkX656aSU6a3EtiMwrM.html

- FARF Website.

http://farf.in/farf/wordpress-4.8/wordpress/research/

- Social and behavioural change communication- Amina Tarraf

- Swachh Bharat Mission sanitation data.

http://swachhbharatmission.gov.in/SBMCMS/writereaddata/images/pdf/technical-notesmanuals/Sanitation-in- Gram-Panchayats.pdf 